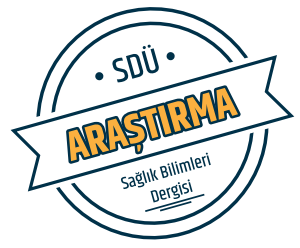

Sdü Sağlık Bilimleri Dergisi / Cilt 10 Sayı 3 / 2019

\title{
Erken Çocukluk Çağı Çürüklerinin Önlenmesinde Annelerin Oral Hijyen Alışkanlıkları ve Çocuk Beslenmesi Konusunda Bilgi Düzeyinin ve Farkındalıklarının Belirlenmesi
}

\section{Determination of Knowledge and Awareness of Mothers' Oral Hygiene Habits of and Child Feeding in the Prevention of Early Childhood Caries}

\author{
Gülhan Ünal Kocaman', Ahmet Taylan Çebi² \\ ${ }^{1}$ Karabük Üniversitesi Diş Hekimliği Fakültesi Periodontoloji Anabilim Dalı, Karabük, Türkiye. \\ ${ }^{2}$ Karabük Üniversitesi Diş Hekimliği Fakültesi Ağız, Diş ve Çene Cerrahisi Anabilim Dalı, Karabük, Türkiye.
}

\section{Özet}

Amaç: Çalışmamızın amacı; 0-6 yaş grubu çocuklarında erken çocukluk çağı diş çürüklerinin görülme sıklığının ve çürük oluşumunda etkili faktörlerin belirlenmesi ve annelerin ağız ve diş sağlığı ile ilgili uygulamalarının çocuklardaki çürük gelişimi üzerindeki etkisini ortaya koymaktır.

Materyal-Metot: Çalışmamıza, 0-6 yaş aralığında çocuğu bulunan 200 gönüllü anne dahil edilmiştir. Gönüllülerin, sosyodemografik özellikleri, oral hijyen alışkanlıkları ve çocuğun beslenme alışkanlıkları ile ilgili toplam 35 soru içeren anketi doldurması sağlanmıştır. Çocuklardaki mevcut diş çürükleri, araştırmacı iki hekim tarafından tespit edilmiştir. Verilerin analizinde yüzde ve frekans dağılımlarından, normal dağılım gösteren parametrelerin değerlendirilmesinde Student $\mathrm{t}$ testi ve ANOVA'dan yararlanılmıştır. Anlamlılık sinırı olarak $\mathrm{p}<0,01$ ve $\mathrm{p}<0,05$ kabul edilmiştir.

Bulgular: Annelerin eğitim düzeylerinin ile çocuklarda görülen erken çocukluk çağı diş çürükleri arasında istatistiksel olarak anlamlı bir ilişki bulunmuştur $(p<0,01)$. Ailelerin yerleşim yerleri ile erken çocukluk çağı çürükleri arasında istatistiksel olarak anlamlı bir ilişki bulunmuştur $(\mathrm{p}<0,05)$. Ailede bulunan çocuk sayısı ile diş çürüğü görülme sıklığı arasında istatistiksel olarak anlamlı ilişki bulunmuştur $(p<0,01)$. Ailenin diş firçalama alıșkanlığ ile erken çocukluk çağı çürükleri arasında istatistiksel olarak anlamlı bir ilişki bulunmuştur $(p<0,05)$. Düzenli diş hekimi kontrolleri ile erken çocukluk çağı çürükleri arasında istatistiksel olarak anlamlı bir ilişki olduğu sonucuna varılmıştır $(p<0,05)$.

Sonuç: Erken çocukluk çağı çürükleri önemli bir halk sağlığı sorunudur. Çalışmamızda, 0-6 yaş grubundaki çocukların annelerinin ağız ve diş sağlığına ilişkin tutumlarının, çocuklarının beslenme alışkanlıklarının erken çocukluk çağ çürüğü oluşumunda etkili olabileceği bulunmuştur.

Anahtar kelimeler: Ağız Hijyeni, Diş Çürükleri, Erken Çocukluk Çağı, Süt Dişleri.

\begin{abstract}
Objective: The purpose of our study is to determine the prevalence of early childhood caries in 0-6 age group children and determination of factors affecting caries formation and to determine the effect of oral and dental health practices of mothers on the development of caries in children.
\end{abstract}

Material-Method: 200 volunteer mothers were included whose children are between 0 and 6 age group. Volunteers were asked to complete a questionnaire which included a total of 35 questions about their sociodemographic characteristics, oral hygiene habits and feeding habits of the child.The existing dental caries in children were identified by two investigating physicians. Percentage and frequency distributions were used for the analysis of the data and Student $t$ test and ANOVA were used for the evaluation of normal distribution parameters. $\mathrm{P}<0,01$ and $\mathrm{p}<0,05$ were accepted as the limit of significance.

Results: A statistically significant relationship was found between the educational level of mothers and early childhood tooth decay in children $(\mathrm{p}<0.01)$. A statistically significant relationship was found between the settlements of the families and early childhood caries $(\mathrm{p}<0.05)$. There was a statistically significant relationship between the number of children in the family and the incidence of dental caries $(p<0.01)$. A statistically significant relationship was found between the toothbrushing habits of the family and early childhood caries $(p<0.05)$. It was concluded that there was a statistically significant relationship between regular dental check-ups and early childhood caries $(\mathrm{p}<0.05)$.

Conclusions: Early childhood caries is an important public health problem. In our study, it was found that the attitudes of mothers of 0-6 age group children on oral and dental health, their child's eating habits to be effective in early childhood caries formation.

Keywords: Oral Hygiene, Dental Caries, Early Childhood, Natal Teeth.
DOI: $10.22312 /$ sdusbed.552632

Müracaat tarihi / Received date: 11.04 .2019

Kabul tarihi / Accepted date: 05.09.2019

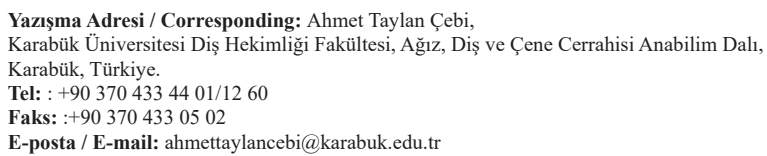




\section{Giriş}

Sağlık, insanlık tarihinde vazgeçilmez bir kavramdır. A ğız ve diş sağlığı, sistemik sağlığın ayrılmaz bir ögesidir. Ağız ve diş sağlığının bozulması, bireylerin yaşam kalitesini ve yaşam doyumunu her alanda olumsuz yönde etkilemektedir. Toplumlarda ağız ve diş sağlığının iyileştirilmesi, ancak toplumsal bir bilincin kazandırılması ve bireysel sağlığın ve bakımın optimal hale getirilmesi ile gerçekleştirilebilir (1).

Çocuklarda en çok rastlanan hastalıklardan biri olan erken çocukluk çağı çürüğü (EÇÇ), kronik ve multifaktöriyel enfeksiyöz bir rahatsılıktır $(2,3)$. EÇÇ; 71 aylık ve daha küçük çocuklarda, birden fazla kavite oluşturmuş ya da oluşturmamış çürük lezyonu, çürük sebebiyle diş kaybı veya herhangi bir süt dişinde dolgulu diş yüzeyinin varlığ 1 olarak tanımlanır (4). EÇÇ’de çürükler, ilk olarak üst ön bölgede görülürler, sonrasında posterior dişleri etkilerler. Mandibular ön bölge dişleri beslenme esnasında dilin koruyuculuğu sayesinde genellikle çürüklerden etkilenmezler (5).

Diş çürüğünün agresif bir şekli olan EÇÇ; biyolojik, fizyolojik ve davranışsal risk faktörleri ile ilişkili olan multifaktöriyel bir hastalıktır (6). Diş çürüğünün etiyolojisinde, mikroorganizmalar, substrat ve konak olmak üzere üç faktörden bahsedilmektedir fakat EÇÇ'nin etiyolojisinde dental plak ve karyojenik bakterilerin daha fazla etkin olduğu bildirilmektedir (7). Ayrıca, düşük sosyoekonomik ve sosyokültürel durum, sık sık karbonhidrat ağırlıklı ara öğün tüketilmesi, annenin sigara tüketimi, annenin diş kaybı ve yaptığı doğum sayısı, florlama, bebek beslenme alışkanlıkları, annenin tükürük Streptococcus mutans seviyesi EÇÇ ile ilişkili olan sosyolojik ve çevresel faktörler arasında sayılmaktadır (8-11).

Süt dişleri; beslenme, fonasyon, çenelerin gelişimi ve estetiğe katkıda bulunmalarının yanında daimi dişlerin yerlerini korumalarıyla da bilinen en iyi yer tutuculardır ayrıca erken dönemde süt dişlerinde görülen çürükler ilerleyen zamanlarda daimi dişlerinde çürümesine neden olmaktadır. $\mathrm{Bu}$ sebeplerden dolayı süt dişlerinin vaktinden önce kaybı, ileri yaşlarda okluzyon bozukluklarına, estetik sorunlara, beslenme problemlerine, anormal dil alıșkanlıklarına, konuşma bozukluklarına ve psikolojik sorunlara yol açabilmektedir. Bu nedenle, fizyolojik düşme yaşına kadar süt dişlerinin sağlıklı ve fonksiyonel bir şekilde ağızda tutulması son derece önemlidir (12).

Erken çocukluk çağı döneminde görülen çürükler sadece çocukları değil aileleri de ilgilendiren bir sağlık sorunudur. Ailenin ağız ve diş sağlığı hakkındaki bilgi ve tutumu çocuklara da yansımaktadır. Annenin çocuğun sağlı̆̆ına gösterdiği ilgi, ağız ve diş sağlı̆̆1 hakkında bilgi, tutum ve davranışı çürük riskini azaltan önemli faktörlerden birkaçını oluşturmaktadır (13).

Bu çalışmada, bir halk sağ lığı sorunu olan EÇÇ'nin önlenmesinde, annelerin ağız ve diş sağlığı uygulamalarının çocuklardaki çürük gelişimi üzerindeki etkisini belirlemek amaçlanmıştır.

\section{Materyal-Metot}

Çalışmaya Etik Kurul kararı (Karar no:10/5, Tarih:01.11.2017) ve ilgili makamlardan gerekli izinler alındıktan sonra başlanmış ve Helsinki İnsan Hakları Bildirisi ile ilgili kılavuz ilkelere uygun olarak yürütülmüştür.

Araştırma, 06.11.2017- 01.02.2018 tarihleri arasında, sosyoekonomik olarak dezavantajlı bölgede yer alan iki farklı devlet okulunda ve farklı sosyoekonomik seviyeye sahip hastaların başvurduğu Ağız ve Diş Sağlığı Merkezi'nde gerçekleştirilmiştir. Araştırmanın örneklemini; okul öncesi (0-6) yaş aralığında çocuğu olan, Türkçe konuşma ve anlama problemi olmayan, 200 anne oluşturmuştur. Çalışmaya katılan gönüllü sayısı Power analizi sonuçlarına göre belirlenmiştir (Tip I hata: 0,05, tip II hata: 0,20 ve çalışmanın gücü 0,80 ve üzeri olarak kabul edilmiștir). Gönüllülük ilkesine özen gösterilerek çalışma grubunu oluşturan bireyler, çalışmanın amaç ve yararları, çalışmadaki rolleri ile ilgili açıklama yapılarak bilgilendirilmiş onamları alındıktan sonra çalışmaya dahil edilmiştir. Verilerin toplanmasında, çalışma grubunun sosyodemografik özelliklerini, annenin oral hijyen alışkanlıklarını, çocuğun oral hijyen alışkanlıklarını ve beslenme alışkanlıklarını değerlendirmeye yönelik 35 soru içeren anket formu kullanılmıştır. Anket sorularının 8 tanesi açık uçlu, 27 tanesi kapalı uçlu sorulardır. Anket verilerinin toplanmasının takibinde çocukların ağız içi muayeneleri araştırmacılar (2 diş hekimi) tarafindan yapılmış ve ağız içerisindeki çürük, dolgulu, kanal tedavili dişler ve çürük sebebiyle erken kaybedilmiş dişler araştırmacılar tarafından kaydedilmiştir.

Verilerin analizinde yüzde ve frekans dağılımlarından, tek değişkenli analizlerde normal dağılım gösteren parametrelerin değerlendirilmesinde Student $t$ testi ve ANOVA'dan yararlanılmıştır. Anlamlılık sınırı olarak $p<0,01$ ve $p<0,05$ kabul edilmiştir.

\section{Bulgular}

$\mathrm{Bu}$ bölümde, çalışma grubundaki annelerin ağız diş sağlığ1 ile ilgili uygulamalarına, sosyodemografik özelliklerine, çocuklarının beslenme ve oral hijyen alışkanlıklarına ilişkin yüzde ve frekans dağılımları ve çocuklardaki diş çürüğünün demografik özelliklerle karşılaştırmalı olarak kıyaslanması verilmiştir.

Yapılan araştırmaya katılan annelerin $(n=200), \% 6,5$ 'nin okula gitmediği, \%20,5'nin ilkokul, \%13'ünün ortaokul, \%31'inin lise, \%29'unun üniversite ve üzeri mezunu olduğu, gelir durumunun \%10,5'inin 1500 TL'den az, \%15'inin 15012000 TL, \%74,5'inin 2001 TL'den fazla olduğu, \%72'sinin yaşamlarının büyük bir kısmında yerleşim yeri olarak ilde yaşadığı, \%28'inin ilçe ve köyde yaşadığ, \% 81,5'inin çekirdek aileye, \%18,5'inin geniş aileye sahip olduğu saptanmıştır (Tablo 1).

Araştırmaya katılan annelerin oral hijyen alışkanlıklarının değerlendirilmesinde, \%99'unun kendisine ait diş firçasının olduğu, \%1'inin ise diş firçasının olmadığı tespit edilmiştir. \%96,5'inin dişlerini firçaladı̆̆ $\breve{1}, \% 3,5$ 'nin ise diş firçalama alışkanlığının olmadığ , diș firçalayan annelerin ise \% 76,5'inin günde birkaç kez diş firçaladığı, \%23'ünün ise haftada birkaç kez dişlerini firçaladığı tespit edilmiştir (Tablo 2). 
Tablo 1. Ailenin sosyodemografik özelliklerine ilişkin bulgular

\begin{tabular}{lllc}
\hline & & $\mathbf{n}$ & $\mathbf{\%}$ \\
\hline Annenin öğrenim durumu & Okula gitmemiş & 13 & 6,5 \\
& İlkokul & 41 & 20,5 \\
& Ortaokul & 26 & 13,0 \\
& Lise & 62 & 31,0 \\
& Üniversite ve üzeri & 58 & 29,0 \\
\hline Gelir durumu & 1500 tl den az & 21 & 10,5 \\
& $1501-2000$ & 30 & 15,0 \\
& 2001 tl den fazla & 149 & 74,5 \\
\hline Yerleșim yeri & İl & 144 & 72,0 \\
& İlçe ve köy & 56 & 28,0 \\
\hline Aile tipi & Çekirdek aile & 163 & 81,5 \\
& Geniş aile & 37 & 18,5 \\
\hline Toplam & & 200 & 100 \\
\hline
\end{tabular}

Tablo 2. Annelerin oral hijyen alışkanlıklarına ilişkin bulgular

\begin{tabular}{llcc}
\hline & & $\mathbf{n}$ & $\mathbf{\%}$ \\
\hline \multirow{2}{*}{$\begin{array}{l}\text { Kendinize ait diş fırçanız var } \\
\text { mı? }\end{array}$} & Evet & 198 & 99,0 \\
& Hayır & 2 & 1,0 \\
\hline \multirow{2}{*}{ Dişlerinizi fırçalıyor musunuz? } & Evet & 193 & 96,5 \\
& Hayır & 7 & 3,5 \\
\hline \multirow{2}{*}{ Ne sıklıkla fırçalıyorsunuz? } & Günde birkaç & 153 & 76,5 \\
& Haftada birkaç & 46 & 23,0 \\
\hline \multirow{2}{*}{ Size diş fırçalama öğretildi mi? } & Evet & 146 & 73,0 \\
& Hayır & 54 & 27,0 \\
\hline \multirow{2}{*}{ Diş fırçalamayı kimden } & Diş hekiminden & 26 & 13,0 \\
ögrendiniz? & Televizyondan & 8 & 4,0 \\
& Eğitim & 33 & 16,5 \\
& Aileden & 87 & 43,5 \\
\hline Toplam & & 200 & 100 \\
\hline & & &
\end{tabular}

Araştırmaya katılan gönüllülerin \%73'üne doğru diş firçalama tekniklerinin öğretildiği, \%27'sine ise öğretilmediği bilgisine ulaşıldı. Diş firçalama tekniğini bilen gönüllülerin, bu bilgiyi, \%13'ünün diş hekiminden, \%4'ünün televizyondan, $\% 16,5$ 'inin ilgili konuyla verilen eğitimlerden, \%43,5'inin ise aileden öğrendiği tespit edilmiştir (Tablo 2).

Çocuklarının oral hijyen alışkanlıklarının değerlendirilmesinde; annelerin \%93'ü çocuğunun kendisine ait diş firçası olduğunu, \%7'si ise olmadığını bildirmişlerdir. Katılımcıların çocuklarının, \%85,5'inin dişlerini firçaladığı, bu diş firçalayanların ise \%60'ının günde birkaç kez, \%29,5'inin ise haftada birkaç kez dişlerini firçaladığı tespit edilmiştir. Annelerin \%72,5'inin çocuklarıyla birlikte diş firçaladıkları tespit edilmiştir. Ebeveynlerin \%92'sinin çocuklarının dişlerini kontrol ettikleri öğrenildi. Katılımcı annelerin \%50,5'i, çocuklarında okul öncesi dönemde çürük dişlerin var olduğunu bildirmişlerdir (Tablo 3).
Tablo 3. Çocuğun oral hijyen alışkanlıklarına ilişkin bulgular

\begin{tabular}{llcc}
\hline & & $\mathbf{n}$ & $\mathbf{\%}$ \\
\hline \multirow{2}{*}{ Çocuğunuza ait diş firçası var mı? } & Evet & 186 & 93,0 \\
& Hayır & 14 & 7,0 \\
\hline \multirow{2}{*}{ Çocuğunuz dişlerini firçalıyor mu? } & Evet & 171 & 85,5 \\
& Hayır & 29 & 14,5 \\
\hline Çocuğunuz dişlerini ne sıklıkla & Günde birkaç & 120 & 60,0 \\
fırçalıyor? & Haftada birkaç & 59 & 29,5 \\
\hline Çocuğunuzla birlikte diş & Evet & 145 & 72,5 \\
fırçalıyor musunuz? & Hayır & 55 & 27,5 \\
\hline Çocuğunuzun dişlerini kontrol & Evet & 184 & 92,0 \\
eder misiniz? & Hayır & 16 & 8,0 \\
\hline Çocuğunuzun okul öncesi (0-7 & Evet & 101 & 50,5 \\
yaş) diş çürüğü var mı? & Hayır & 99 & 49,5 \\
\hline Toplam & & 200 & 100 \\
\hline & & &
\end{tabular}

Tablo 4. Çocuğun beslenme alışkanlıklarına ilişkin bulgular

\begin{tabular}{llcc}
\hline & & $\mathbf{n}$ & $\mathbf{\%}$ \\
\hline \multirow{2}{*}{ Çocuğunuz anne sütü aldı mı? } & Evet & 191 & 95,5 \\
& Hayır & 9 & 4,5 \\
\hline \multirow{2}{*}{ Çocuğunuz geceleri anne sütü aldı mı? } & Evet & 187 & 93,5 \\
& Hayır & 13 & 6,5 \\
\hline Çocuğunuzun beslenmesinde biberon & Evet & 117 & 58,5 \\
kullandınız mı? & Hayır & 83 & 41,5 \\
\hline \multirow{2}{*}{ Çocuğunuz gece biberon ile beslendi mi? } & Evet & 91 & 45,5 \\
& Hayır & 109 & 54,5 \\
\hline $\begin{array}{l}\text { Cocuğunuzun beslenmesinde biberon } \\
\text { içine tatlandırıcı (şeker, reçel, bal vb.) }\end{array}$ & Evet & 56 & 28,0 \\
kullandınız mı? & Hayır & 144 & 72,0 \\
\hline & & &
\end{tabular}

Araştırmaya katılan annelerin $\% 95,5$ 'i çocuğunun anne sütüyle beslendiğini, \%93,5'i çocuklarının geceleri anne sütü aldığını, $\% 58,5$ 'i çocuklarının beslenmesinde biberon kullandığını, $\% 45,5$ 'i geceleri biberonla çocuklarını beslediğini ve biberonla besleyen annelerin \%28'inin biberonun içerisine tatlandırıcı (şeker, reçel, bal vb.) kullandığını bildirmişılerdir (Tablo 4).

Annelerin eğitim seviyesi ile EÇÇ arasında istatistiksel olarak ileri düzeyde anlamlı bir ilişki bulunmuş $(p<0,01)$, eğitim seviyesi yükseldikçe çürük varlığının azaldığı tespit edilmiştir. Ebeveynlerin yaşadığı yerleşim yerleri ile EÇÇ arasında istatistiksel olarak anlamlı bir ilişki bulunmuş $(p<0,05)$, ilde yaşayan ebeveynlerin çocuklarındaki diş çürüğü varlığı daha az olarak tespit edilmiştir. Gelir durumu ve aile tipi ile EÇÇ arasında istatistiksel olarak anlamlı bir ilişki bulunmamıştır $(\mathrm{p}>0,05)$. Ailedeki çocuk sayısı ile EÇÇ arasında istatiksel olarak ileri düzeyde anlamlı ilişki bulunmuş $(p<0,01)$, ailedeki çocuk sayısı arttıkça diş çürüğü varlığı daha fazla olarak tespit edilmiştir. Annenin diş firçalama sıklığı ile EÇÇ arasında istatistiksel olarak ileri düzeyde anlamlı bir ilişki bulunmuş $(p<0,01)$, günlük düzenli diş firçalayan annelerin çocuklarındaki diş çürüğü varlığı daha az tespit edilmiştir. Çocuklarla birlikte diş firçalama ve çocuklarının diş kontrolleri 
ile EÇÇ arasında istatiksel olarak anlamlı bir ilişki bulunmuş $(\mathrm{p}<0,05)$, anneleriyle birlikte diş furçalayan çocuklardaki çürük varlığı ve düzenli olarak diş hekimi kontrolü yapılan çocuklardaki çürük varlığı anlamlı düzeyde daha az olarak tespit edilmiştir. Çocuklardaki diş firçalama ve diş firçalama sıklığı ile EÇÇ arasında istatiksel olarak anlamlı bir ilişki bulunmamıştır ( $\mathrm{p}>0,05)$ (Tablo 5).

Tablo 5. Çocuklardaki diş çürüğünün sosyodemografik özelliklerle kiyaslanmas1

\begin{tabular}{|c|c|c|c|c|}
\hline & & \multicolumn{2}{|c|}{ Diş çürüğğü } & \multirow[b]{2}{*}{ p } \\
\hline & & $\begin{array}{c}\text { Evet } \\
\text { n }\end{array}$ & $\begin{array}{c}\text { Hayır } \\
\text { n }\end{array}$ & \\
\hline \multirow{5}{*}{ Anne eğitim } & Okula gitmemiş & 8 & 5 & \multirow{5}{*}{$\mathrm{p}=0,01$} \\
\hline & İlkokul & 27 & 14 & \\
\hline & Ortaokul & 17 & 9 & \\
\hline & Lise & 28 & 34 & \\
\hline & Üniversite ve üzeri & 21 & 37 & \\
\hline \multirow{3}{*}{ Gelir durumu } & 1500 tl den az & 12 & 9 & \multirow{3}{*}{$\mathrm{p}=0,103$} \\
\hline & $1501-2000 \mathrm{tl}$ & 20 & 10 & \\
\hline & 2001 tl den fazla & 69 & 80 & \\
\hline \multirow{2}{*}{ Yerleşim yeriniz } & $\overline{\mathrm{İl}}$ & 67 & 77 & \multirow{2}{*}{$\mathrm{p}=0,045$} \\
\hline & İlçe ve köy & 34 & 22 & \\
\hline \multirow{2}{*}{ Aile tipiniz } & Çekirdek aile & 81 & 82 & \multirow{2}{*}{$\mathrm{p}=0,384$} \\
\hline & Geniş aile & 20 & 17 & \\
\hline \multirow{4}{*}{ Çocuk sayısı } & 1 & 15 & 44 & \multirow{4}{*}{$\mathrm{p}=0,000$} \\
\hline & 2 & 47 & 32 & \\
\hline & 3 & 23 & 17 & \\
\hline & 4 ve üzeri & 16 & 6 & \\
\hline \multirow{2}{*}{$\begin{array}{l}\text { Annenin diş } \\
\text { fırçalama sıklığı }\end{array}$} & Günde birkaç & 68 & 85 & \multirow{2}{*}{$\mathrm{p}=0,009$} \\
\hline & Haftada birkaç & 32 & 14 & \\
\hline \multirow{2}{*}{$\begin{array}{l}\text { Çocuk diş } \\
\text { firçalama }\end{array}$} & Evet & 90 & 11 & \multirow{2}{*}{$\mathrm{p}=0,103$} \\
\hline & Hayır & 81 & 18 & \\
\hline \multirow{2}{*}{$\begin{array}{l}\text { Çocuk } \\
\text { firçalama sıklığı }\end{array}$} & Günde birkaç & 60 & 60 & \multirow{2}{*}{$\mathrm{p}=0,212$} \\
\hline & Haftada birkaç & 34 & 25 & \\
\hline \multirow{2}{*}{$\begin{array}{l}\text { Birlikte diş } \\
\text { furçalama }\end{array}$} & Evet & 43 & 102 & \multirow{2}{*}{$\mathrm{p}=0,024$} \\
\hline & Hayır & 38 & 17 & \\
\hline \multirow{2}{*}{$\begin{array}{l}\text { Çocuk diş } \\
\text { kontrol }\end{array}$} & Evet & 89 & 95 & \multirow{2}{*}{$\mathrm{p}=0,036$} \\
\hline & Hayır & 12 & 4 & \\
\hline
\end{tabular}

\section{Tartışma}

Bu çalışmada EÇÇ’nin, annelerin oral hijyen alışkanlıkları, çocuklarına yansıtmaları ve eğitmeleri, çocuklarının beslenmeleri ile ilişkisi incelenmiştir.

Eğitim seviyesi yüksek ailelerin ağız ve diş sağlığı hakkındaki bilgi ve farkındalık seviyeleri de yüksek olduğundan bu ailelerin çocuklarının da bilgi düzeyinin yüksek olduğunu ve dolayısıyla da diş çürüğü sayılarının az olduğunu bulan çalışmalar mevcuttur (14-17). Bizim çalışmamızda da bu sonuçlarla paralel olarak, annenin eğitim seviyesi ile erken çocukluk çağı diş çürükleri arasında bir ilişki olduğu, eğitim seviyesi yükseldikçe diş çürük oranının azaldığı sonucuna varılmıştır.
Chu ve ark. ve Hosseinpoor ve ark. çalışmalarında ortalama çürük diş sayılarının ekonomik durumla ilişkili olduğunu, düşük ekonomik duruma sahip ailelerin çocuklarının ortalama diş çürük sayılarının, yüksek ve orta ekonomik duruma sahip ailelerin çocuklarına oranla daha fazla olduğunu bildirmişlerdir $(16,18)$. Bizim çalışmamızda ise, ekonomik durum ile EÇÇ arasında herhangi bir ilişki tespit edilmemiştir. Bunun nedenini ise, araştırmaya katılan annelerin çoğunun, ekonomik durumları ne olursa olsun diş firçalama alışkanlıklarına sahip olmalarına ve çocuklarına yansıtmalarına bağlamaktayız.

Chu ve ark. ve Armfield yaptığı çalışmalarda yerleşim yerinin gerek çürük oluşumunu gerekse bireylerin ağız ve diş sağlığ1 bilgi ve farkındalıklarını etkilediğini bildirmişlerdir $(16,19)$. Bizim çalışmamızda, ilçe ve köy yerinde yaşayan çocuklarda, il merkezinde yaşayan çocuklara oranla daha çok EÇÇ'ye rastlandığı bulunmuştur. Bu durumu ilçe ve köyde yaşayan bireylerin sağlık kurumlarına ulaşım ve sosyal olanaklarının sinırlılığı, beslenme farklılıkları, yaşantı alanlarının farklılıkları, sosyoekonomik değişkenliklere bağlamaktayız.

Ayrancı çalışmasına katılan bireylerden düzenli diş firçalayanların firçalamayanlara oranla daha az çürüğü olduğunu saptarken, Lourenco ve ark. çalışmalarında diş firçalama sıklığı ile çürük sayısı arasında anlamlı fark saptamamışlardır $(20,21)$. Çalışmamızda da Lourenco ve ark.nın yaptıkları çalışmanın sonucu ile paralel olarak, çocuklardaki diş firçalama ve diş firçalama sıklığı ile EÇÇ arasında anlamlı bir ilişki bulunmamıştır (21).

Erken çocukluk gelişiminin desteklenmesinde ailenin rolü oldukça büyüktür (22). Yapılan araştırmalar sonucunda da; erken çocukluk döneminde çocuklara verilen eğitimlere aile katılımının, sadece çocuk açısından değil aynı zamanda, aile açısından da faydalarının olduğu saptanmıştır (23). Çalışmamızın sonucunda da; annelerin çocuklarının dişlerini kontrol etmesi ve beraber diş fırçalama alışkanlıklarının olması gibi durumların çocuklardaki ağız ve diş sağlığı bilincini arttırması ve EÇÇ’nin görülme sıklığı üzerinde olumlu bir etkisi olduğu bulunmuştur.

Biberon ile beslenme EÇÇ oluşumunu arttırmaktadır. Biberonun meme kısmı tükürüğün üst keser dişlere geçişini engeller. Gece tükürük akışı ve tükürük tamponlama kapasitesi azalmakta ve biberon kullanımı ile ağızda uzun süreli fermente olabilen karbonhidrat birikimi gerçekleşmektedir (24). Bizim çalışmamızda da katılımcıların \%58,5'inin çocuklarının beslenmesinde biberon kullandıkları ve \%28'inin biberonun içerisindeki mamaya ilaveten şeker miktarı fazla olan ve karyojenik etkileri yüksek olan bal, şeker, reçel vb. ürünleri ilave ettikleri bildirilmiştir.

Wellappuli ve Amarasena çalışmalarında ailedeki çocuk sayısının, bebeğin doğum ağırlığının, kardeşler arasındaki yaş farkının çürük tecrübesi ile ilişkisinin olduğunu bildirmişlerdir (25). Bizim çalışmamızda da ailedeki çocuk sayısı ile EÇÇ arasında istatistiksel olarak anlamlı bir ilişki bulunmuş, çocuk sayısı arttıkça EÇÇ bulunma oranının arttığı görülmüştür. Bu durum, çocuk sayısı arttığında ebeveynlerin çocuklar üzerine düşen ilgi ve alakalarında bölünme olmasına, ailedeki birey 
sayısının artmasıyla da bireylerin profesyonel ağız sağlığı hizmetlerinden yararlanmalarını ve sağlıklı bir çevrede yaşamalarını tehlikeye atacak finansal, sosyal ve materyal dezavantajları yaşamalarına bağlanabilir.

Misra ve ark. yaptıkları çalışmalarında annenin ağız bakımı ve kayıp diş sayısı ile çocuklarda çürük düzeyi ile arasında bir ilişki bulmuşlardır (26). Bu sonuca paralel olarak, bizim çalışmamızda annenin diş firçalaması ile çocuklarda görülen EÇÇ arasında bir ilişki bulunmuş, annelerin diş firçalama sıklığı arttıkça, çocuklarında görülen diş çürüğü sayısının azaldığı gösterilmiştir.

\section{Sonuç}

Çocukluk döneminin en sık rastlanan hastalıkların başında gelen EÇÇ ile ilişkili çok sayıda sosyal ve davranışsal risk faktörü bulunmaktadır; ancak EÇÇ, doğru bilgi ve yerinde müdahaleler ile önlenebilmektedir. EÇÇ'den korunma stratejilerinde genel yaklaşımlar; ailenin çocuğun ağız sağlığı, bakımı ve beslenmesi konusunda bilgilendirilmesi, rutin diş hekimi kontrolleri ve ailenin çocuk sağlığı üzerinde kontrolleri şeklinde olmalıdır. EÇÇ eğitimi için aile odaklı programların oluşturulmasına ihtiyaç duyulmaktadır.

\section{Kaynaklar}

1. Vishwanathaiah S. Knowledge, attitudes, and oral health practices of school children in davangere. Int J Clin Pediatr Dent 2016; 9(2): 172-176.

2. Kagihara LE, Niederhauser VP, Stark M. Assessment, management, and prevention of early childhood caries. J Am Acad Nurse Pract 2009; 21(1): 1-10.

3. Thitasomakul S, Thearmontree A, Piwat S, Chankanka O, Pithpornchaiyakul W, Teanpaisan R, et al. A longitudinal study of early childhood caries in 9- to 18-month-old Thai infants. Community Dent Oral Epidemiol 2006; 34(6): 42936.

4. Takaoka LA, Goulart AL, Kopelman BI, Weiler RM. Enamel defects in the complete primary dentition of children born at term and preterm. Pediatr Dent 2011; 33(2): 171-6.

5. Özer S, Şen Tunç E. Erken Çocukluk Çağı Çürükleri. Atatürk Üniv. Diş Hek. Fak. Derg. 2009; 19(2): 115-12.

6. Wyne AH. Early childhood caries: nomenclature and case definition. Community Dent Oral Epidemiol 1999; 27: 313315.

7. Begzati A, Bytyci A, Meqa K, Latifi-Xhemajli B, Berisha M. Mothers' behaviours and knowledge related to caries experience of their children. Oral Health Prev Dent 2014; 12: 133-140.

8. Bedos C, Brodeur JM, Arpin S, Nicolau B. Dental caries experience: a two-generation study. J Dent Res 2005; 84 : 931-936.

9. Kagihara LE, Niederhauser VP, Stark M. Assessment, management, and prevention of early childhood caries. J Am Assoc Nurse Pract 2009; 21: 1-10.

10. Russell SL, Ickovics JR, Yaffee RA. Exploring potential pathways between parity and tooth loss among American women. American Journal of Public Health 2008; 98: 12631270 .

11. Tinanoff N, Reisine S. Update on early childhood caries since the Surgeon General's Report. Academic Pediatrics 2009; 9: 396-403.

12. Law CS. Management of premature primary tooth loss in the child patient. J Calif Dent Assoc 2013; 41: 612-618.

13. Güneş G, Çelik Seyitoğlu D, Şahin S. Malatya Sıtmapınarı ASM 'ye Başvuran 2-4 Yaş Çocuğu Olan Annelerin Çocuklarının Diş Sağlığına Ait Bilgi Düzeyi ve Uygulamaları. Med-Science 2016; 5(1): 72-85.

14. Stephen A, Krishnan R, Ramesh M, Kumar VS. Prevalence of early childhood caries and its risk factors in 18-72 month old children in Salem, Tamil Nadu. J Int Soc Prev \& Comm Dent 2015; 5: 95-102.

15. Branden VDS, Broucke VDS, Leroy R, Declerck D, Hoppenbrouwers $\mathrm{K}$. Oral health and oral health-related behaviour in preschool children: evidence for a social gradient. Eur J Pediatr 2013; 172(2): 231-7.

16. Chu CH, Ho PL, Lo EC. Oral health status and behaviours of preschool children in Hong Kong. BMC Public Health, 2012; 12: 767 .

17. Hassoy H, Ergin I, Meseri R, Mermer G, Erdem H. İzmir ili Kemalpaşa ilçesi ilköğretim öğrencilerinde ağız-diș sağlığı durumu ve ilişkili sosyoekonomik etmenler. İzmir Dr. Behçet Uz Çocuk Hast Dergisi, 2013; 3(2): 97-104.

18. Hosseinpoor AR, Itani L, Petersen PE. Socio-economic inequality in oral healthcare coverage: Results from the World Health Survey. J Dent Res 2012; 91: 275-81.

19. Armfield, J. Socioeconomic inequalities in child oral health: a comparison of discrete and composite area-based measures. J Public Health Dent 2007; 67: 119-125.

20. Ayrancı Ü. Bir grup ilkokul öğrencisinde diş çürüğü saptama araştırması. STED 2005; 14(3): 50-54.

21. Lourenco CB, Saintrain MV, Vieira AP. Child, neglect and oral health. BMC Pediatr 2013; 13: 188.

22. Özmert EA. Erken çocukluk gelişiminin desteklenmesiIII. Aile. Çocuk Sağlığı ve Hastalıkları Dergisi 2006; 49: 256273.

23. Yazar A, Çelik M, Kök M. Aile Katılımının Okul Öncesi Eğitimde ve 2006 Okul Öncesi Eğitim Programındaki Yeri. Atatürk Üniversitesi Sosyal Bilimler Enstitü Dergisi 2008; 12(2): 234-243.

24. Ribeiro NME, Ribeiro MAS. Breastfeeding and early childhood caries:a critical review. J Pediatr 2004; 80: 199210.

25. Wellappuli N, Amarasena N. Influence of family structure on dental caries experience of preschool children in Sri Lanka. Caries Res 2012; 46: 208-12.

26. Misra S, Tahmassebi JF, Brosnan M. Early childhood caries--a review. Dent Update 2007; 34(9): 556-8, 561-2, 564. 